\title{
Management of violent behaviour in acutely relapsed schizophrenics
}

L Koen, MMed(Psych), MBChB, Department of Psychiatry, University of

Stellenbosch, Stikland Hospital

BH Lategan, MBChB, Department of Psychiatry, University of Stellenbosch, Stikland Hospital

E Jordaan, PhD, Biostatistics Unit, Medical Research Council, Bellville

DJH Niehaus, MMed(Psych), MBChB, Department of Psychiatry, University of

Stellenbosch, Stikland Hospital

RA Emsley, DMed, MMed(Psych), FCPsych, MBChB, Department of Psychiatry, University of Stellenbosch, Stikland Hospital

\section{Acknowledgements: This study was supported by the Harry and Doris Crossley Foundation.}

\section{Abstract}

The management of aggressive behaviour has always been a criticai issue in psychiatry. Finding measures that can be used to accurately predict the likelihood of assaultative behaviour and thus ensure timeous appropriate pharmacological management remains a dilemma. The study objective was to investigate the naturalistic, pharmacological management of inpatient aggressive behaviour in a group of 50 schizophrenic subjects with a view to determine: (1) whether a presenting history of recent violence lead to altered pharmacological management and (2) whether the NOSIE could be regarded as a useful assessment tool with regards to inpatient behaviour management. No significant difference could be demonstrated between the 2 subsets of subjects (history of violence vs none) with respect to total doses of medication administered. No statistical correlation could be found between the total NOSIE score and the dose of psychotropic medication used. The relationship between a subset of NOSIE-items and the total dose of medication was more complex and a clear linear relationship could be demonstrated for a total score of 0 to 5 . In this particular ward setting a presenting history of recent violent behaviour did not influence the administration of medication and neither could the clinical judgement employed by the nursing staff to manage inpatient behaviour be captured by the NOSIE. However, a five-item subset of the NOSIE with questions relating to aggression and irritability warrants further scrutiny in this regard.

\section{Abstrak}

Die hantering van aggressiewe gedrag is een van die kritiese vraagstukke in psigiatrie. Dit bly 'n dilemma om assesseringskale te vind waarmee die waarskynlikheid van die voorkoms van aggressie akkuraat voorspel kan word en die resultate derhalwe aangewend kan word vir toepaslike farmakologiese ingrepe. Die doel van hierdie studie was om die naturalistiese farmakologiese hantering van binnepasiënt aggressiewe gedrag in ' $n$ groep van 50 skisofrenie pasiente te bestudeer met die oog daarop om te bepaal: (1) of ' $n$ presenterende geskiedenis van onlangse aggressie lei tot veranderde farmakologiese hantering en (2) of die NOSIE as " $n$ bruikbare assesseringskaal benut kan word met betrekking tot binnepasient gedragshantering. Geen beduidende verskil kon gedemonstreer word tussen die twee groepe (geskiedenis van aggressie vs geen) met verwysing na die totale dosis medikasie toegedien nie. Geen statistiese korrelasie kon gevind word tussen die totale NOSIE-telling en die dosis psigotrope medikasie toegedien nie. Die verhouding tussen "n subgroep van NOSIE-items en die totale dosis medikasie toegedien was meer kompleks en 'n duidelike liniêere verhouding kon gedemonstreeer word vir ' $n$ totale telling van 0 to 5. Binne hierdie spesifieke saalomgewing word die toediening van medikasie nie beïnvloed deur ' $n$ presenterende geskiedenis van onlangse aggressiewe gedrag nie. So ook kon die verpleegstaf se kliniese oordeel met betrekking tot die hantering van binnepasiënt gedrag nie deur die NOSIE vasgevang word nie. 'n Vyf-item NOSIE-subgroepvrae wat betrekking het op aggressie en irritasie benodig egter spesifiek verdere ondersoek in hierdie opsig. 


\section{Background}

Despite the fact that aggressive behaviour occurs only in a small minority of schizophrenia patients, the image of the violent schizophrenic patient is a common misperception in the public's mind (Ehmann et al, 2001:716; Volavka, 1999:43). Furthermore, the media also propagates the assumed conventional and very destructive stereotype of a clear and definite association between violence and mental disorder. As illustrated by Johnston (Johnston and Taylor, 2003:819), media representation of violent acts committed by people with mental disorders tends to be that of images of random, serious violent acts against strangers whereas studies of general psychiatric patients do not support this representation. In actual fact few cases of serious or homicidal violence have been reported and such acts are also more likely to be against intimates than strangers.

Although it is important to address these public misconceptions, the truth is that mental health workers, due to their therapeutic relationship with patients, are in fact very familiar with the consequences of violent behaviour when it does occur (Hector, 1998:466). Ehmann et al (2001:716), reported that the incidence of assaultative behaviour by psychiatric inpatients on mental health workers in the United States reached $23 \%$, compared to the 1-year prevalence of $2 \%$ in the general population. In a study by Currier $(2000: 21)$, done at psychiatric emergency services in the United States, high rates of violence by patients towards staff were found: the mean number of assaults per year at each site was 8,0 (SD+/- 17,5), of which 56,5\% resulted in lost time from work. There was a $6: 1$ odds ratio of nurses being assaulted relative to doctors, most likely related to nurses' role in restraint application.

These incidents increase morbidity in hospitalized patients, interfere with clinical recovery (Pabis and Stanislav, 1996:278) and cause serious bodily harm to patients and staff. Furthermore, it may necessitate restrictive interventions such as seclusion and restraint, which significantly affect morale among patients and staff (Chengappa et al, $2000: 827$ ). Violence also impacts directly on treatment costs due to, amongst others, days lost due to disability amongst staff members, possible legal action and compensation as well as high-intensity management, e.g. 1 : 1 nursing and Xrays.

Aggression occurs in several psychiatric disorders, including agitated depression, mania, panic disorder, general anxiety disorder, dementia, delirium, substance induced agitation, acute psychosis and even akathisia. It is also known that the greater the number of psychiatric diagnoses, the higher the risk of violence (Volavka, 1999:43). Furthermore, schizophrenia patients frequently show higher rates of assault than other diagnostic categories (Ehmann et al, 2001:716)

Four clinical characteristics contribute overwhelmingly to the risk of violence among persons with mental illness: (a) acute, poorly controlled illness; (b) non-compliance with medication; (c) substance abuse, particularly alcohol; and (d) past history of violent behaviour (Buckley, 1999:52; Hector, 1998:466; Soyka, 2000:345; Swartz et al, 1998:75). With specific reference to psychotic disturbances, symptoms such as persecutory delusions and control and command hallucinations have also been found to be related to aggression.

Preventative measures or rapidly effective treatment is thus essential to avoid the potential risk of violence or self-harm. However very little has changed in the treatment of aggressive patients since the beginning of the 1970's (Allen, 2000:3) and currently there is no agent approved or licensed for the management of aggressive behaviour. This issue is further compounded in that psychiatric hospitals often do not have clear protocols with regards to the management of violent behaviour. Currier $(2000: 21)$ found that only $6 \%$ of psychiatric emergency services in the United States had precise, written protocols guiding the medication type, dosage and route of administration during acute incidents of aggression.

Considering how violent behaviour influences the acute management of mental illness, it is surprising that this area has received so little attention and that it has not been the target of more clinical trials. One reason may be that, as reported by Buckley (1999:52), pharmacological studies on aggressive patients are extremely difficult to conduct. $\mathrm{Ob}$ stacles include ethical concerns, the validity of informed consent and lack of appropriate research settings. Accordingly, much of the reported literature is based on augmentation trials, most often as case series rather than rigorously conducted clinical trials.

In the clinical setting a variety of psychotropics of different classes have been tried for the management of acute aggression (Buckley, 1999:52), but there seems to be contradicting views with regards to the use of the different agents. Prior to the development of the second-generation antipsychotics, high-potency conventional antipsychotics (prototype: haloperidol) had been the treatment of choice for the stabilization of acute psychosis among hospitalized schizophrenic patients (Feifel, 2000:27). Benzodiazepines have also achieved popularity because of their safety and tolerability and according to a study by Allen (2000:11), all available evidence suggests that benzodiazepines are at least as effective as haloperidol alone.

Furthermore, despite the perceived advantages of the newer, second-generation antipsychotics, a study by Ereshefsky (1999:20) reported that rapid calming is not always evident in many patients with orally administered second generation medication and that, during the crisis management phase for patients with psychotic disorders, a continuing need for intramuscular therapy using benzodiazepines, neuroleptics or combinations of both still exists.

Therefore, although current research advocates the use of benzodiazepines and second generation antipsychotics rather than conventional neuroleptics (Allen, 2000:3) in the acute setting, benzodiazepines and typical antipsychotics are often still clinically regarded as the first choice for man- 
aging acute aggression, with second-generation antipsychotics more often utilized for persistent aggression (Allen, 2000:11) Currier, 2000):21).

To date, empirical studies are also limited by lack of uniformity in defining aggression and violence. Some studies have referred to violence as both verbal and physical aggression, others as only physical aggression, and still others as physical aggression that resulted in significant injury (Hughes and Kleespies, 2003:10).

Therefore, considering the practical implications, it should also be clear that differing definitions of what constitutes violent behaviour must surely also lead to differing views from clinical staff as to which behaviours need to be addressed with medication and also at what time this intervention is most appropriate. Thus finding measures that can be used to accurately predict the likelihood of assaultative behaviour and thus ensure timeous appropriate pharmacological management remains a priority.

The Nurse's Observation Scale for Inpatient Evaluation (NOSIE), a psychiatric ward behaviour scale, originated in the United States and was introduced by Honigfeld 37 years ago. This scale is a rating scale designed to assess clinical changes in long-stay schizophrenic patients (Philip, 1977:467). In its current form the NOSIE comprises 30 items grouped into six scales: social competence, social interest, personal neatness, irritability, manifest psychosis and retardation. Few studies investigating the use of the NOSIE are available. Some studies suggest that the NOSIE is a valid and reliable scale, (Honigfeld et al, 1966:180; Philip, 1977:46729) especially in chronic care patients (Pattison and Rhodes, 1974:200), while a study by Hafkenscheid found that the scale had limited predictive value (Hafkenscheid, 1991:46).

We could find only one study that evaluated the use of the NOSIE to predict assaults among acute psychiatric patients (Swett and Mills, 1997:1177). This study evaluated the NOSIE, the Brief Psychiatric Rating Scale (BPRS), and the Mini Mental State Examination (MMSE) as predictors of assault that occurred during psychiatric evaluation. Patients who committed assaults during hospitalization and those who did not were compared. A high score on the irritability factor of the NOSIE and failure to complete the MMSE correctly predicted the occurrence of assault in $81 \%$ of cases.

In this naturalistic study of schizophrenia inpatients, subjects' immediate pharmacological management in the first four days following an admission for an acute exacerbation of illness was documented. Nursing staff were also asked to complete two scales (NOSIE and the Overt Aggression Scale (OAS) (Yudovsky et al, 1986:35)) with regards to inpatient behaviour during the first four days of admission. It was hypothesized that the nursing staff's observations as expressed by the total NOSIE score at day 4 would not correlate with increased benzodiazepine and/or antipsychotic use in acutely relapsed schizophrenia inpatients. As a secondary hypothesis it was also postulated that a history of previous violent behaviour would not lead to a dif- ference in the immediate pharmacological management of these patients.

\section{Methodology}

Fifty consecutively admitted subjects with a DSM-IV diagnosis of schizophrenia, with at least one prior admission to a psychiatric hospital, were recruited within 24-hours of their admission to the twenty four-bed acute male tertiary care unit at Stikland State Psychiatric Hospital in Bellville, Western Cape. This hospital serves a large population of urban and rural patients.

The study had a naturalistic, retrospective design and the treating physician and nursing staff did not have access to the study assessments. No prescriptive guidelines for treatment were provided. Medication records were investigated retrospectively.

To clinically assess their current behaviour, all subjects were interviewed within 24 hours of admission, before any medication was administered. On day 4 after admission, the nursing staff completed a NOSIE (see Table 1) on each patient with regards to inpatient behaviour in the preceding four days. The OAS was also completed by nursing staff on day 4 in order to assess whether discreet episodes of violence had occurred during the admission.

The Diagnostic Interview for Genetic Studies (DIGS) (Nurnberger et al, 1994:849) was conducted on day eight after admission to allow for some improvement of the acute psychosis and thus optimize the quality of biographic information obtained from the patient. Further collateral with regards to previous behaviour was obtained from previous case notes, the hospital file and family members, where possible.

The subjects were divided into a violent and non-violent subset according to the presence or absence of any previously documented/reported or currently exhibited violent behaviour as defined by Koen et al (2004:254). This definition included at least one of the following - a lifetime history of physical violence against self, others or objects as reported by the patient or family or previously recorded in clinical notes, or significant verbal threats as reported by family or observed during interviews conducted on the day of admission.

All medication given to each patient during the first four days of admission was recorded retrospectively. The medication was divided into three groups: benzodiazepines, antipsychotics and other medication. All benzodiazepines were converted to the equivalent dose of lorazepam and antipsychotics to the equivalent dose of chlorpromazine, to enable cross comparison of drugs.

\section{Primary statistical analysis}

I. The total score of the NOSIE.

2. The total score on a five-item subset of the NOSIE (see Table 1; Items 2, 10, 12, 18, 29) This subset of 


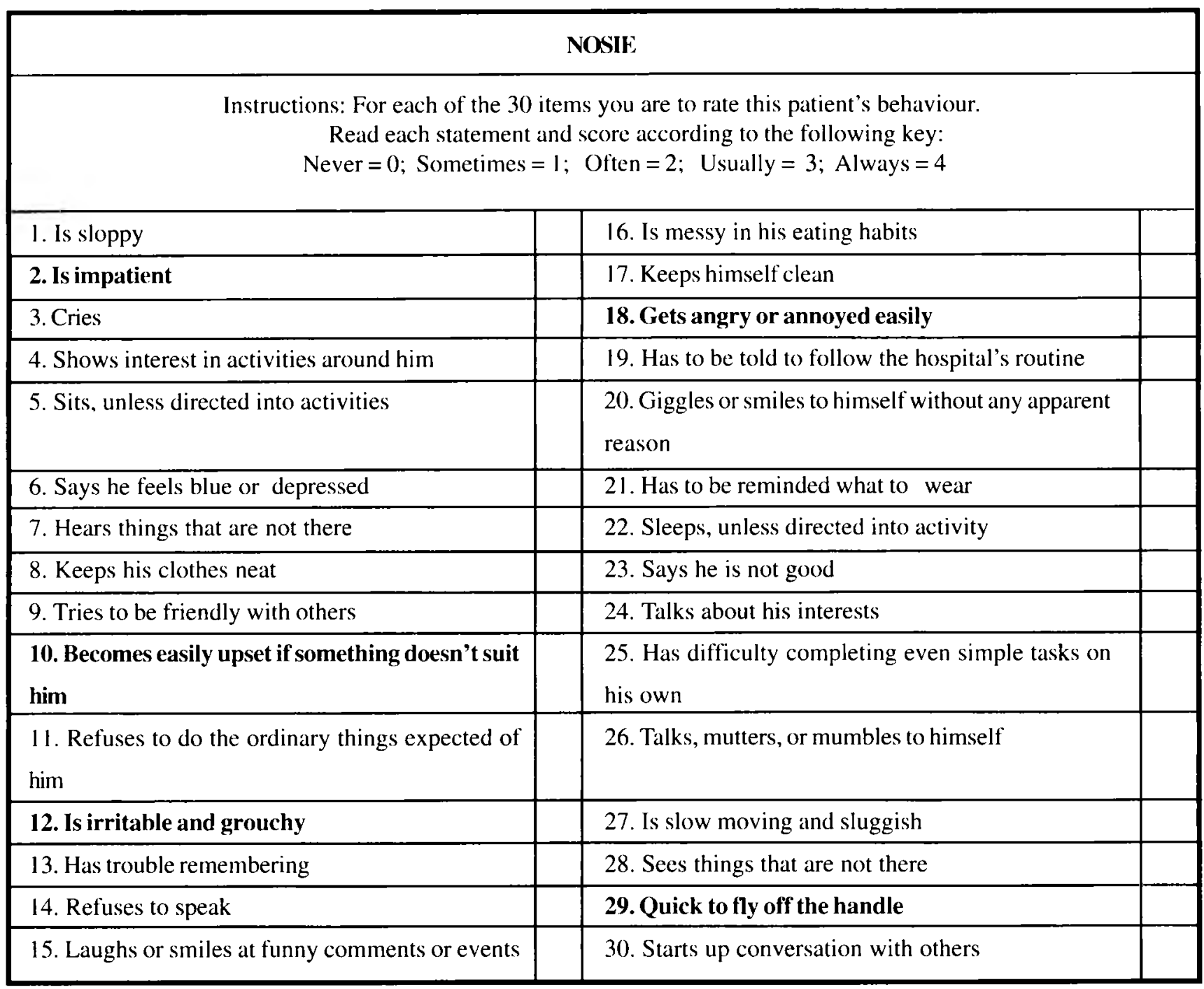

questions represented all items of the NOSIE that reflect observations with regard to irritability and aggression.

3. Total dose of benzodiazepines (lorazepam equivalents) and the total dose of antipsychotics (chlorpromazine equivalents) were calculated.

4. Scatterplots (with lowest smoothing) were used to show the relationship between total antipsychotic and benzodiazepine dose (sum of all doses from baseline to Day 4) and the total score on the NOSIE.

5. Scatterplots were then repeated for the total five item score.

\section{Secondary statistical analysis}

1. Demographic variables were described in terms of descriptive statistical measures (frequencies, means, standard deviation, range) specific to each variable.

2. A descriptive analysis was done of all subjects that scored positive on the OAS.

3. T-tests (independent samples) were performed to investigate possible relationships between the antipsychotic and benzodiazepine use and a positive score on the OAS.
4. T-tests (independent samples) were performed to investigate possible relationships between the antipsychotic and benzodiazepine use and a positive history of violence as defined by Koen et al (2004:254).

Prior to the administration of any study procedures, written informed consent was obtained from all participants and from their legal guardian/caretaker if any doubt existed as to the ability of the patient to offer consent. The study was approved by and conducted according to the stringent ethical norms laid down by the ethics committee of the University of Stellenbosch. In accordance with this patients were clearly informed that they were allowed to withdraw consent at any stage, that their participation would remain confidential and that non-participation in the study would not affect their current or future treatment in any way.

\section{Results}

Of the group of 50 subjects 25 were allocated to the violent group and 25 to the non-violent group in accordance with the definitions previously described. Seven subjects had an incident of inpatient aggressive behaviour recorded on 


\begin{tabular}{|llll|}
\hline & Violent Group & Non-violent Group & Significance \\
& \% & $\mathbf{\%}$ & $\boldsymbol{\chi}^{\mathbf{2}, \mathbf{p}}$ \\
\hline Employment status at diagnosis (unskilled) & 60 & 77 & $2.21,0.14$ \\
Employment status at present (unemployed) & 75 & 77 & $0.03,0.87$ \\
Marital status (married) & 35 & 27 & $0.56,0.46$ \\
Alcohol abuse & 53 & 23 & $\mathbf{6 . 2 7 , 0 . 0 1 2}$ \\
Cannabis use & 33 & 27 & $0.28,0.597$ \\
Paranoid delusions & 63 & 63 & $0.01,0.94$ \\
Grandiose delusions & 43 & 43 & $0.005,0.944$ \\
Delusions of control & 73 & 47 & $\mathbf{4 . 8 4 , 0 . 0 2 8}$ \\
Auditory hallucinations & 73 & 70 & $0.05,0.82$ \\
Visual hallucinations & 8 & 20 & $2.38,0.12$ \\
\hline
\end{tabular}

the OAS, constituting nearly $15 \%$ of the study population. All 7 of these subjects had been allocated to the violent group on admission.

The total group consisted of 38 Coloured subjects, 5 Caucasian and 7 of African descent. A comparison of basic demographic and clinical factors including current marital status, level of education, number of admissions, history of medication coinpliance, substance abuse and presence of perceptual disturbances or delusions revealed no significant differences between the violent and non-violent subsets except with regards to lifetime history of alcohol abuse and presence of delusions of control which were both significantly higher in the violent group_(See table 2).
NOSIE score and the total dose of either antipsychotics (expressed as chlorpromazine equivalents) $(\mathrm{p}=0.778)$ or benzodiazepines (expressed as lorazepam equivalents) $(p=0.131)$. However, the relationship between the total score of the five subset items and the total dose of either antipsychotics or benzodiazepines is more complex. Although there seems to be no linear relationship (fig I), it is worth noting that a clear linear relationship exists for a total score of 0 to 5 , and only if the score is higher than 5 does this relationship disappear. This is most likely due to the small number of individuals scoring higher than a total of 5 on these items. In fact, considering a five-item score of less or equal to 5 , a significant correlation is indicated $(n=45$, $r=0.547, p=0.0001)$ for the benzodiazepine use. For the
Medication given to the violent versus non-violent subgroup during the first 4 days did not differ significantly with respect to either total benzodiazepines $(p=0.105)$ or total antipsychotics $(\mathrm{p}=(0.767)$. Also, when comparing the subgroup of seven subjects who had a violent incident on the ward to the rest of the group, no difference could be demonstrated for either antipsychotics $(p=0.174)$ or oral benzodiazepines $(\mathrm{p}=0.777$ ). However, this group did receive significantly more intramuscular lorazepam (as well as total benzodiazepines) $(p=0.006)$. The mean amount of benzodiasepines in the OAS-group was $18 \mathrm{mg} / 4$ days, while the rest of the group received a mean of only $6,55 \mathrm{mg} / 4$ days.

No significant relationship could be demonstrated between the total

\section{Benzodiasepine Total vs Five Item Subset Total Fig 1}

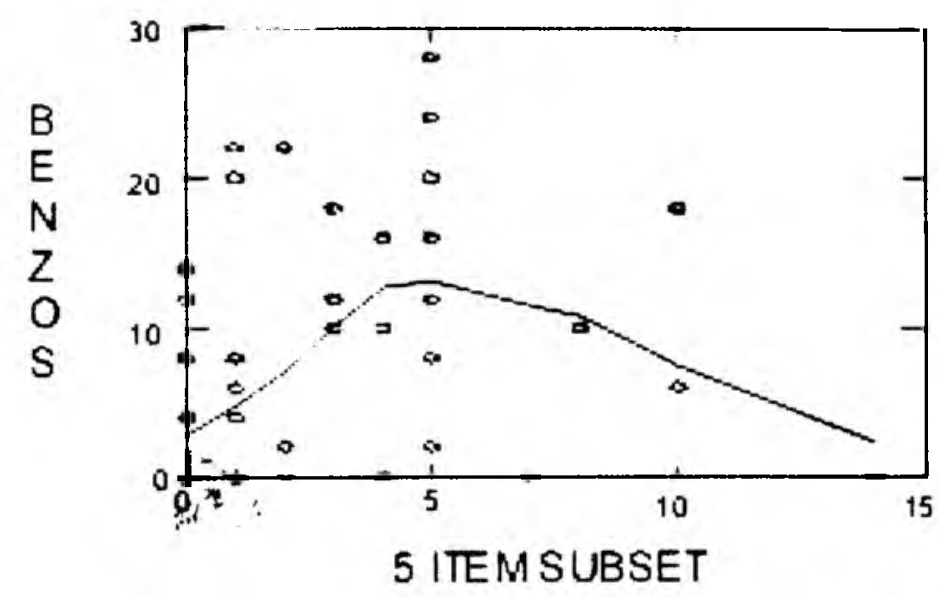




\section{Antips ychotic Total vs Five Item Subset Total Fig 2}

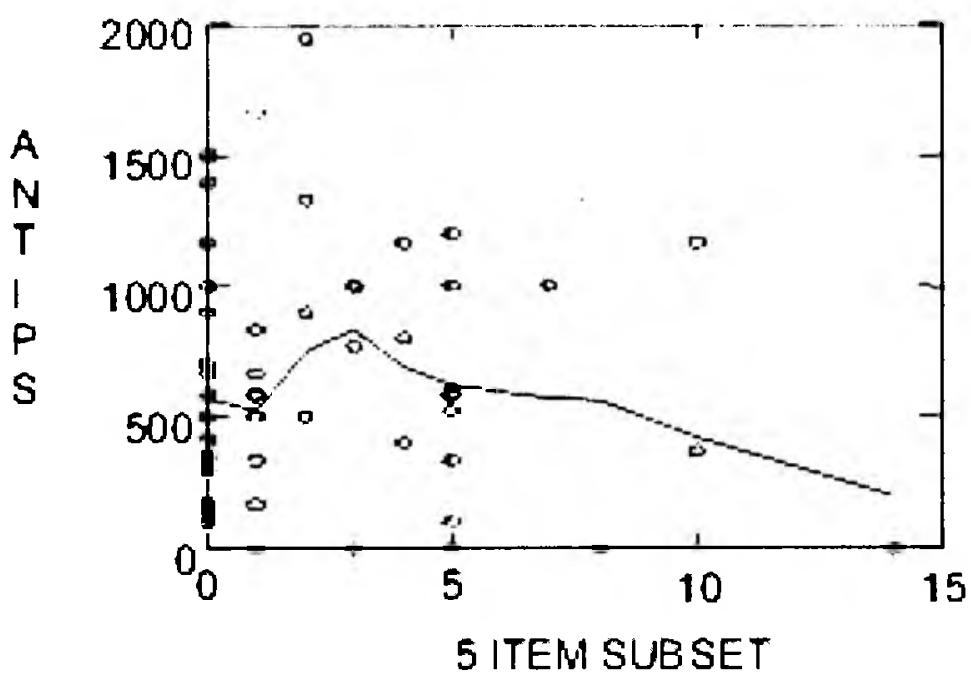

behaviours tend to be mostly due to their illness and should thus generally lend themselves to proactive management (Buckley, 1999:52). Not surprisingly, reduced levels of threatening behaviour, agitation and assault leads to a marked reduction in staff injury with a commensurate improvement in staff and patient morale and a dramatic improvement in the social environment (Mallya et al, 1992:395). A clear need exists for the identification of those patients most at risk for violent behaviour in order to be able to effectively implement pro-active treatment regimes as well as other appropriate preventative measures.

In our study, no difference could be demonstrated in the amount of antipsychotics, benzodiazepines antipsychotics (fig 2), this decrease might be more real. In terms of the aggressive incidents reported on the OAS; in 6 of the 7 cases the aggressive incident resulted in the patient being placed in seclusion, with the seventh case being managed only with a verbal intervention by two members of the nursing staff. The other 6 cases all resulted in members of staff having to physically restrain the subjects prior to seclusion. In two cases the combination of verbal intervention, physical restraint and seclusion proved to be an adequate intervention but in the other 4 cases sedation was needed. All subjects were sedated with lorazepam with doses ranging from $2-4 \mathrm{mg}$. In all cases ward management protocol was followed and none of the incidences led to serious injury to the patient or staff members.

Comparing the group of 7 subjects to the total study population $(n=50)$ in terms of selected clinical and demographic data yielded the following: Only 2 of the subjects had been compliant with antipsychotic medication prior to admission (similarly reflected in $21 \%$ of the total), all 7 had a history of violence prior to this admission compared to 25 ( 7 included) for the total group. $42.9 \%$ presented with alcohol abuse in the week prior to admission compared to $52.5 \%$ of the violent subset and $40 \%$ of the total. $42.9 \%$ tested positive for cannabis use compared to $42.5 \%$ of the violent subset and $30 \%$ of the total group. The only variable that was shared by all 7 subjects ( $100 \%$ ) was the presence of delusions of control with the comparative figures $72.5 \%$ of the violent subset and $61 \%$ of the total group.

\section{Discussion}

Despite its relatively low prevalence, aggressive behaviour in a psychiatric setting has a major effect on morale amongst staff and patients when it occurs. Not only do patients with schizophrenia have to cope with the symptoms of their debilitating illness, they often also bear the consequences of their violent behaviour even though these or any combination administered when compared to the total NOSIE score. Therefore, the clinical judgement employed by the nursing staff to determine psychotropic use in the management of inpatient behaviour could not be captured by the NOSIE as no correlation between increased medication use and total scores could be shown. However, a possible linear relationship could be demonstrated between treatment dose and a score of 0-5 on a five item subset. Unfortunately, due to the small sample size, this could not be deliniated further.

Furthermore, no difference in the administration of psychotropics between the violent and non-violent subsets could be demonstrated. Therefore, in this particular ward setting, the presence of a history of violent behaviour did not lead to any pro-active pharmacological management, even though a number of studies (Blomhoff et al, 1990:771; Convit et al, 1988:429; Karson and Bigelow, $1987 ; 161$ ) have demonstrated that previous violent behaviour serves as a predictor of future violence.

Importantly however, the subgroup of seven violent subjects (OAS positive) did receive statistically more intramuscular (as well as total) benzodiazepines compared to the rest of the study population. This further underlines the fact that in this particular setting violence was not proactively managed but rather treated when it actually occurred. As all 7 of these subjects had originally formed part of the violent subset, a pro-active management plan could in fact have prevented these incidents.

As mentioned in the background, the literature is not entirely consistent with regards to the pharmacological management of violence. Some studies support the use of either benzodiazepines or antipsychotics equally for the management of acute aggression (Dorevitch et al, 1999:142; Salzman, 1991:177). Other studies support the use of a combination of antipsychotics and benzodiazepines. Current 
management protocols in the Western Cape for primary and secondary care facilities suggest the initial use of lorasepam, followed by haloperidol if an adequate response is not achieved within a 30 minute window.

Worldwide, the treatment of aggression in the acute inpatient setting appears to show a move from a combination of benzodiazepines and typical antipsychotics, towards the combination of benzodiazepines and atypical antipsychotics. However, as the atypical antipsychotics are mostly unavailable in our psychiatric setting, they cannot factor into current treatment practices.

The results of our study seem to indicate that current clinical prescription practice at Stikland Hospital favours the use of intramuscular benzodiazepines for the management of acute aggression in the inpatient setting. This would be in keeping with the primary and secondary management protocol, with the exception that antipsychotics are seldom added in the inpatient setting because the patient is either already receiving antipsychotics or the added benefits of the ability to seclude a patient makes further administration of medication unnecessary.

The results would also seem to support the hypothesis that current clinical practice in this unit favours the approach of managing aggressive behaviour when it occurs rather than to pro-actively manage patients who are at higher risk for violent behaviour. Despite the inherent difficulties in predicting violence, subjects admitted to this particular unit have previously been show to be at high risk if: 1. A history of previous violent behaviour was present and 2. Alcohol abuse took place in the week preceding admission (Koen et al, 2004:254). Therefore, specifically using criterium number one, the 7 violent incidents described could have been proactively managed as all were committed by subjects who had been documented on admission to have a history of violent behaviour. In this particular setting attention should possibly also be paid to the presence of delusions of control during the mental status examination on admission as this was the only other characteristic that was shared by the group of seven. It should be kept in mind however that a proactive management protocol would have led to other subjects receiving more medication even though they did not eventually resort to a specific violent act on the ward. Therefore, in order to try and delineate even further which subjects are at risk for inpatient violence, an evaluation tool that captures the nursing staff's clinical judgement would be of great value to facilitate proactive management of only those subjects who are at highest risk for resorting to violent behaviour_during hospital admission.

Unfortunately the NOSIE, as used in this study, failed to capture the clinical judgement employed by the nursing staff to determine psychotropic use in the management of inpatient behaviour as no correlation could be shown between increased medication use and total scores. The subset of 5 questions however bears further scrutiny as some correlation could be identified with regards to the administration of benzodiasepines. Further research in a larger sample is needed to address the issue of whether this NOSIE subset score would be useful in determining where an increased need for preventative measures and therefore timeous pharmacological intervention exists.

Limitations of this study mainly centred on inherent difficulties with the definition of violence, the small number of subjects (especially those with high subset scores) and the reliance on previous history with possible recall bias.

\section{References}

ALLEN MH 2000: Acute care of the agitated psychotic patient. Journal of Clinical Psychiatry. 61 (S14), 3-4

ALLEN MH 2002: Emergency Psychiatry (review of psychiatry series, volume 21 , number 3 : Oldham JM and Riba $\mathrm{MB}$, series editors). Washington DC, American Psychiatric Publishing, 115-43

ALL.EN MH 2000: Managing the agitated psychotic patient: a reappraisal of the evidence. Journal of Clinical Psychiatry. 61 (S 14), 11-20

BLOMHOFF S, SEIMS, FRIISS 1990: Can prediction of violence among psychiatric inpatients be improved? Hospital and Community Psychiatry. 41, 771-5

BUCKLEY PF 1999: The role of typical and atypical antipsychotic medication in the management of agitation and aggression. Journal of Clinical Psvchiatry. 60 (S 10), 52-9

CHENGAPPA KN, IEVINEJ, ULRICHR, PAREPALLY H, BRAR JS, ATZERT R, BRIENZO R, GOPALANI A 20M): Impact of risperidone on seclusion and restraint at a state psychiatric hospital. Canadian Journal of Psychiatry. 45, $827-32$

CONVIT A,JAEGER J,LINSP, MEISNER M, VOI_AVKA J 1988: Predicting assaultiveness in psychiatric inpatients: A pilot study. Hospital and Communitv Psvchiatry. 39, 429. 34

CURRIER GW 2000: Atypical antipsychotic medications in the psychiatric emergency service. Journal of Clinical Psychiatry. 61 (S 14), 21-6

DOREVITCHA,KATZ N,ZEMISHLANY Z,AIZENBERG D, WEIZMANN A 1999: Intramuscular flunitrazepam versus intramuscular haloperidol in the emergency treatment of aggressive psychotic behaviour. American Journal of Psvchiatry. 156, 142-4

EHMANN TS,SMITHGN, YAMAMOTOA,MCCARTHY N, ROSS D, AU T, FLYNNSW, ALTMAN S, HONER WG 2001: Violence in treatment resistant psychotic inpatients. Journal of Nervous and Mental Disease. 189, 716-21

ERESHEFSKY L 1999: Pharmacologic and pharmacokinetic considerations in choosing an antipsychotic. Journal of 
Clinical Psvchiatry. 60 (S 10), 20-30

FEIFEL D 2000: Rationale and guidelines for the inpatient treatment of acute psychosis. Journal of Clinical Psvchiatry, 61 (S 14), 27-32

HAFKENSCHEID A 1991: Psychometric evaluation of the NOSIE in the Netherlands. Acta Psvchiatrica Scandinavica. $83,46-52$

HECTOR RI 1998: The use of clozapine in the treatment of aggressive schizophrenia. Canadian Journal of Psychiatry. $43,466-472$

HONIGFELDG, GILLIS RD, KLETT CJ 1966: NOSIE-30: a treatment-sensitive ward behaviour scale. Psvchology Report. 19, 180-2

HUGHES DH, KLEESPIES PM 2003: Treating aggression in the psychiatric emergency service. Journal of Clinical Psvchiatry. 64. 10-5

JOHNSTON I, TAYLOR PJ 2003: Mental disorder and serious violence: the victims. Journal of Clinical Psvchiatry, 64, 819-24

KARSON C, BIGELOW LB 1987: Violent behaviour in schizophrenia inpatients. Journal of Nervous and Mental Disease. $175,161-4$

KOEN L, KINNEAR CJ, CORFIELD VA, EMSLEY RA, KEYTER N, MOOLMAN-SMOOK J, STEIN DJ, NIEHAUS DJH 2004: Violence in male patients with schizophrenia: risk markers in a South African population. Australian and New Zealand Journal of Psvchiatry. 38, 254-9

MALLYA AR, ROOS PD, ROEBUCK-COLGAN K 1992: Restraint, seclusion and clozapine. Journal of Clinical Psychiatry. 23, 395-7

NURNBERGER JI, BLEHAR MC, KAUFMANN CA, YORK-COOLER C, SIMPSON SG, HARKAVY-FRIEDMAN J, SEVERE JB, MALASPINA D, REICH T 1994: Diagnostic interview for genetic studies. Rationale, unique features, and training. NIMH Genetics Initiative. Archives of General Psychiatry. 51, 849-59

PABIS DJ, STANISLAV SW 1996: Pharmacotherapy of aggressive behaviour. Annals of Pharmacotherapy. 30, 27887

PATTISON EM, RHODES RJ 1974: Clinical prediction with the NOSIE-30 scale. Journal of Clinical Psychology. 30, 2001

PHILIP AE 1977: Cross-cultural study of the factorial dimensions of the NOSIE. Journal of Clinical Psychology. 33, $467-8$

SALZMANC 1991: Parenteral lorazepam versus parenteral haloperidol for the control of psychotic disruptive behav- iour. Journal of Clinical Psvchiatry. 52, 177-80

SOYKA M 2000: Substance misuse, psychiatric disorder and violent and disturbed behaviour. British Journal of Psychiatry. 176, 345-50

SWARTZ MS, SWANSON JW, HIDAY VA, BORUM R, WAGNER R, BURNS BJ 1998: Taking the wrong drugs: the role of substance abuse and medication non-compliance in violence among severely mentally ill individuals. Social Psychiatry Epidemiology. 33, S75-S80

SWETT C, MILLS T 1997: Use of the NOSIE to predict assaults among acute psychiatric patients. Psvchiatric Services. 48. $1177-80$

VOLAVKA J 1999: The effects of clozapine on aggression and substance abuse in schizophrenic patients. Journal of Clinical Psvchiatry. 60)(S 12), 43-6

YUDOVSKYSC,SILVER JM,JACKSON W, ENDICOTT J, WILLIAMS D 1986: The Overt Aggression Scale for objective rating of verbal and physical aggression. American Journal of Psvchiatry. 143, 35-9 